\title{
O inovador lançamento de In Rainbows: contribuição para o debate sobre direitos autorais na cena digital
}

Gisela G. S. Castro ${ }^{1}$

Doutora em Comunicação e Cultura pela Universidade Federal do Rio de Janeiro - ECO/UFRJ e coordenadora do Programa de Mestrado em Comunicação e Práticas de Consumo da Escola Superior de Propaganda e Marketing (ESPM), São Paulo, onde desenvolve pesquisa sobre o consumo de música na internet.

E-mail: castro.gisela@gmail.com

Resumo: A partir da entrada em cena das novas tecnologias de produção, distribuição e consumo de música, assistimos a um processo de intensa reconfiguração na indústria fonográfica. Enfocando a polêmica em torno do lançamento do álbum In Rainbows da banda independente britânica Radiohead, este artigo pretende contribuir para o debate sobre as complexas temáticas da pirataria e dos direitos autorais na cena digital.

Palavras-chave: música digital, consumo, internet, direitos autorais, pirataria.
Abstract: New technologies of music production, distribution and consumption have triggered intense reconfiguration in the phonographic industry. By analyzing the recent polemic release of the album In Rainbows by British independent band Radiohead, this article intends to contribute to the debate on the complex issues of piracy and property rights in the digital scene.

Keywords: digital music, consumption, internet, copyrights, piracy.

Analisando a estetização e a espetacularização do cotidiano como principais produtos da cultura midiática atual, podemos compreender o papel central do entretenimento e das paisagens audiovisuais como eixos organizadores dos padrões econômicos e socioculturais do mundo contemporâneo. Não é exagero afirmar que o som gravado ocupa lugar de destaque, sendo o ouvir música uma prática emblemática do dia-a-dia de parcelas significativas das populações do planeta.

A indústria fonográfica vive uma etapa na qual seu principal modelo de negócios - a venda de CDs - é confrontado por novas modalidades de

Recebido: 06.10 .2008

Aprovado: 08.10 .2008

1. Disponível em: $<$ http://lattes.cnpq.br/ 3110538732969465>. 
2. Disponível em: <http:// www.myspace.com>.

3. International Federation of the Phonographic Industry (http://www.ifpi. org) e Recording Industry Association of America (http://www.riaa.com) respectivamente. consumo, possibilitadas pela entrada em cena de tecnologias de produção e distribuição surgidas na esteira do desenvolvimento da microinformática e das redes telemáticas em escala global.

A apropriação social de tecnologias digitais de criação, gravação, distribuição e consumo de música ocasiona, dentre outros fatores, a explosão do compartilhamento de conteúdo on-line e o fortalecimento da chamada produção independente.

O ideal de um acervo virtual aparentemente ilimitado e diversificado, constantemente atualizado e ampliado pelos próprios usuários, atrai fãs de música em todo o mundo, consolidando a rede como arena preferencial no consumo de música digital. Mesmo com certo atraso, a indústria fonográfica investe na digitalização de seu acervo e na consolidação das vendas de música on-line. Todo o esforço da indústria fonográfica nos últimos anos visa atender a uma demanda bastante explícita de consumidores que ouvem música nos mais variados lugares e situações, utilizando tocadores portáteis ou mesmo telefones celulares de última geração.

No bojo da reconfiguração em curso na cadeia produtiva da música, novos atores entram em cena - como as operadoras de celular - e o longo oligopólio das quatro majors (Sony-BMG, Universal Music, Warner Music e EMI) sofre significativos abalos. A nosso ver, a polêmica acerca da ciberpirataria e da revisão dos direitos autorais necessita ser examinada à luz das novas práticas de consumo vigentes na cultura digital.

Dentre os novos hábitos de consumo, revela-se particularmente polêmico o compartilhamento gratuito de arquivos de áudio on-line. Por meio desse tipo de prática, milhões de internautas em todo o mundo trocam música e ampliam seus conhecimentos acerca de músicas e bandas em blogs e redes sociais como o $M y S_{\text {Space }}^{2}$. A indústria fonográfica majoritária, representada pela IFPI e RIAA ${ }^{3}$, considera o compartilhamento gratuito um ato de pirataria, por ferir as leis vigentes de proteção aos direitos autorais. Artistas e bandas se dividem ao opinar sobre a questão.

A partir da popularização do padrão MP3 de compactação de arquivos de áudio e de aplicativos de compartilhamento via internet, como o pioneiro Napster, tornou-se mais fácil entrar em contato com a produção de novas bandas ou artistas, bem como encontrar na web antigas e raras gravações já fora de catálogo.

Um arquivo em formato MP3 ocupa 1/12 do espaço de um arquivo não-compactado, facilitando sua transmissão pela rede e reduzindo de modo significativo o tempo necessário para o download. Já existem padrões com maior capacidade de compactação e melhor qualidade de reprodução, mas o MP3 continua sendo o mais difundido ainda hoje.

Lutando judicialmente e em bloco contra o compartilhamento gratuito, a indústria fonográfica aposta no download comercial de música, que tem como entraves a coexistência de diversos padrões e formatos digitais, tornando incompatíveis conteúdos e tocadores de marcas concorrentes, além 
da percepção disseminada entre os consumidores de que o preço cobrado por CDs é abusivo. Devido a essas questões, a imagem da indústria fonográfica junto ao público, assim como parte da própria classe artística, ficou seriamente abalada. Para muitos músicos e bandas, hoje, a cena independente - em suas diversas interfaces com o jogo majoritário das principais distribuidoras - é tida como preferencial para a comercialização de seus trabalhos.

Não é raro observar cantores, compositores e bandas que disponibilizam seu material gratuitamente via internet, no intuito de se lançar no mercado musical. A principal fonte de renda desses músicos seria a venda de ingressos e/ou os cachês cobrados para apresentações ao vivo. Construir uma base de fãs por meio da internet tornou-se viável na era da cibercultura. Esse processo de fidelização de clientela frequentemente conjuga plataformas de compartilhamento de conteúdo e a homepage do artista ou banda em questão, aliada a blogs e redes de relacionamento através dos quais artistas e fãs podem manter contato mais direto.

Estratégias multifacetadas como essas são também adotadas como parte do esquema promocional de artistas consagrados ligados a grandes gravadoras, indicando a internet como um cenário privilegiado para a consolidação da relação entre fãs e seus ídolos.

No sempre competitivo mercado fonográfico, as mais variadas estratégias são utilizadas no marketing de novos produtos musicais. A seguir, vamos examinar o surpreendente lançamento do álbum In Rainbows, pela banda britânica Radiohead.

\section{FÃS, PIRATAS OU LADRÕES?}

Após o estrondoso sucesso comercial e de público obtido com o lançamento do álbum OK Computer, em 1997, a banda britânica Radiohead sagrou-se como uma das mais inovadoras do mercado mundial. Tornou-se independente com o fim da vigência do seu contrato com a Capitol Records, uma subsidiária da gigante EMI, logo após o lançamento do aclamado álbum Hail to the Thief, em 2003. É curioso que o título desse trabalho em uma versão livre para o português seria Saudações ao ladrão - parece incentivar, ainda que de forma brincalhona, a já estabelecida prática do compartilhamento de música on-line, que tanta dor de cabeça tem dado às grandes gravadoras.

O status de banda independente permitiu ao Radiohead lançar seu álbum seguinte, In Raibows, diretamente através de seu website oficial ${ }^{4}$, em outubro de 2007. Numa atitude pioneira, a banda conclamou seus fãs a atribuírem, eles próprios, o valor a ser pago pelo download do material. Esta inovação, que tomou de surpresa o mercado, serve de mote para esta breve reflexão acerca da pirataria e dos direitos autorais no mundo digital.

4. Disponível em: <http:// www.radiohead.com/deadairspace/>. 
comunicação \& educação • Ano XIV • Número 1 • jan/abr 2009

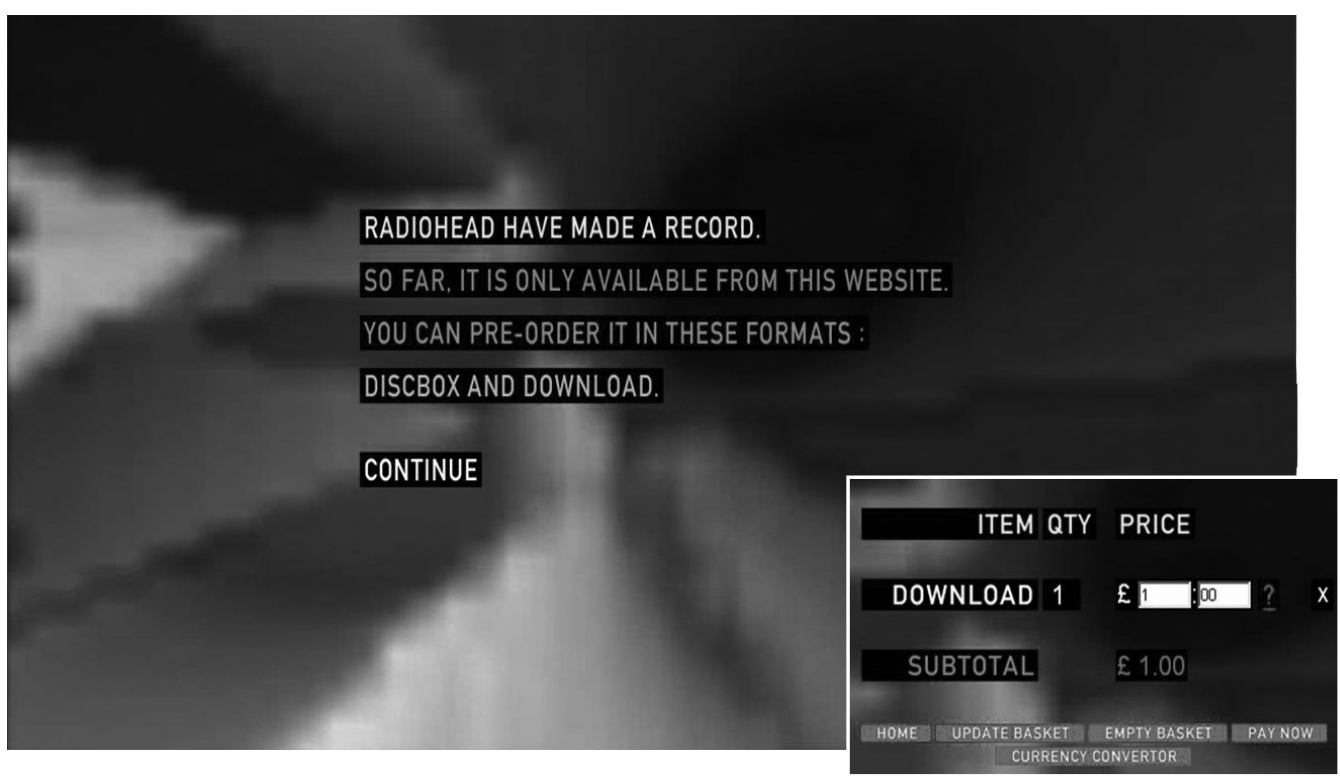

Página do site da banda britânica Radiohead à época do lançamento de In Rainbows. No detalhe, tela de orientação para dowload do álbum. Disponível em: <http://www.music2dot0.com/archives/47>.

Importa notar que tal iniciativa, disponível por tempo limitado, precedeu o lançamento convencional do mesmo álbum em formato CD e também em box contendo ainda um CD bônus, fotos e livro. Apesar de não ter havido a divulgação oficial dos dados da campanha original, sabe-se que a maioria dos fãs optou por pagar pelo download, tendo o número de pagantes excedido o total de adeptos do download gratuito ${ }^{5}$. Uma parcela significativa destes optou por pagar mais caro pelo download direto através do site do que o custo do CD que estaria nas lojas em pouco tempo.

5. Na verdade, o preço final incluía uma taxa fixa de 45 centavos de libra por download.

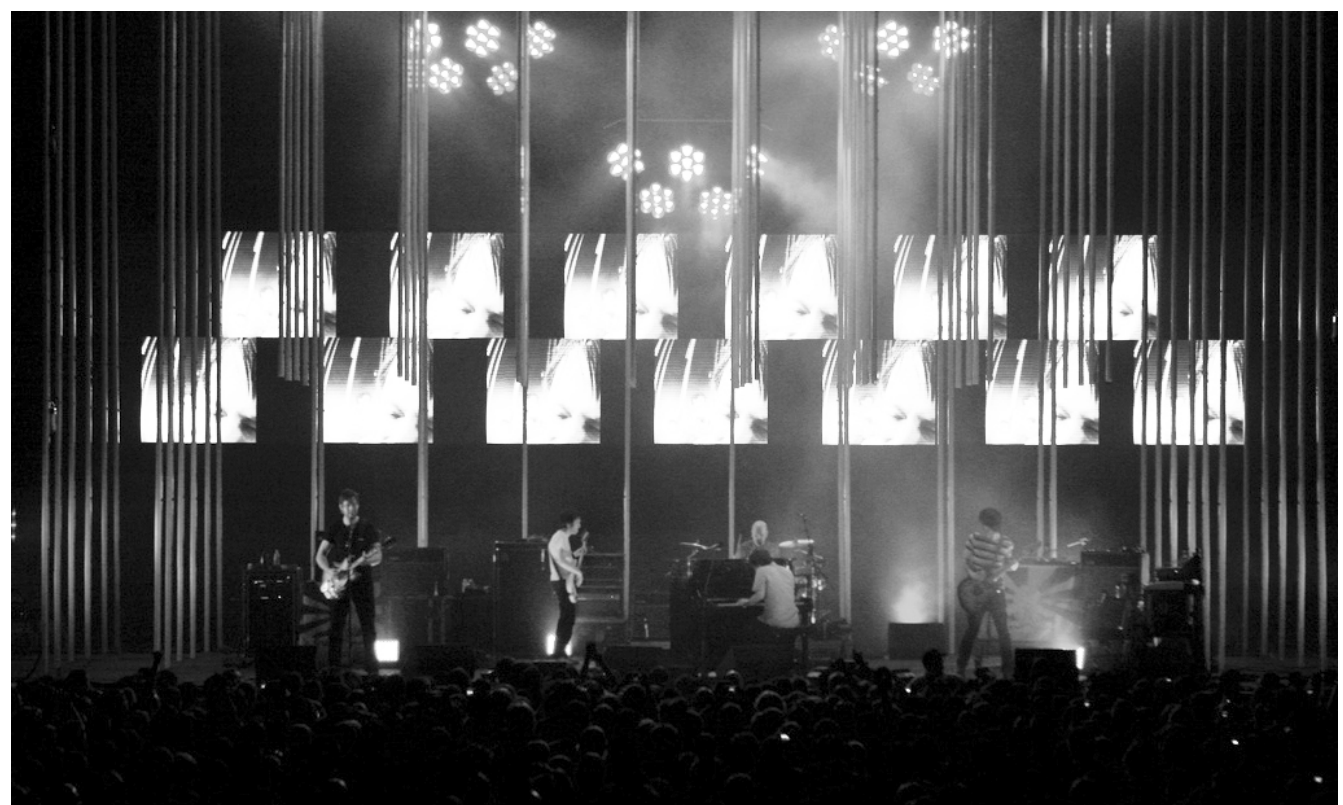

Integrantes do Radiohead, no show Live in Dallas. Dallas (EUA), maio de 2008. Disponível em: <http://gorillavsbear.blogspot.com/2008_05_01_archive.html>. 
Esse curioso comportamento aparentemente altruísta pode ser creditado ao fato de esses compradores valorizarem a oportunidade de obter o álbum antes de seu lançamento oficial nas lojas. É também adequado supor que esse público estaria mais disposto a pagar pelo trabalho quando a renda parecesse voltar-se mais diretamente à banda, e não aos costumeiros intermediários da cadeia produtiva da música, constituída por artistas, gravadoras, produtoras, distribuidoras, pontos de venda e, por fim, consumidores.

Funcionando como arena de contato mais direto entre artista e público, a internet permite certo grau de desintermediação da produção e distribuição musical. Respostas como as observadas por ocasião do lançamento de In Raibows revelam que o consumidor final se mostra atento e aberto a constituir novas práticas de consumo de música digital.

\section{MÚSICA ON THE GO}

Como dissemos, tocadores portáteis de música e seus fones já são parte integrante da cena urbana contemporânea. Com capacidade de armazenamento cada vez maior, teclas shuffle - termo que significa embaralhar em inglês -, design arrojado e tamanho diminuto, esses gadgets atuais, descendentes diretos do Sony Walkman da década de 1980, rapidamente se tornaram um must de consumo, consolidando a prática do encapsular-se em um envelope acústico personalizado onde quer que se esteja.

Através da tecla shuffle, a seleção de músicas a serem tocadas é realizada randomicamente (ao acaso, a esmo, sem seleção ou critério de escolha), de forma automática. Alguns modelos de players digitais permitem ao usuário controlar o grau de aleatoriedade desejado. Sendo a portabilidade e a mobilidade atributos importantes para os atuais fãs de música, a oferta de música on the go (especialmente preparadas para consumo durante os deslocamentos das pessoas) tende a crescer para acompanhar a demanda.

Grandes coleções de música são hoje contabilizadas em gigabytes ${ }^{6}$, acompanhando a exponencial capacidade de memória de HDs, pendrives e players portáteis. Alardeando declínio nas vendas de CDs, gravadoras distribuem música em outros formatos. Plataformas comerciais como i-Tunes ${ }^{7}$ e similares oferecem fonogramas individuais, playlists ou álbuns completos para download.

Outra modalidade de distribuição que atrai milhões de adeptos é o sistema de assinaturas mensais por meio de plataformas virtuais como Rhapsody ${ }^{8}$ e congêneres, que disponibilizam música pelo sistema de streaming ${ }^{9}$. Um artigo recente, publicado na revista Time ${ }^{10}$, especula sobre o eventual ocaso do sistema de assinaturas pagas com o consolidação do novo serviço MySpace Music. O streaming é uma modalidade de distribuição on-line que permite acesso ao conteúdo sem que o internauta possa copiá-lo em seu HD. Em outras palavras, por meio desse sistema pode-se ouvir, mas não
6. Uma típica canção popular em formato MP3 tem cerca de 5 megabytes. Considerando que 1 megabyte $=10^{6}$ bytes, enquanto 1 gigabyte = $10^{9}$ bytes, a quantidade de canções estocadas em gigabytes é ainda extraordinária.

7. Plataforma virtual da Apple Computers, pioneira em comercializar música diretamente para tocadores digitais (<http://www. itunes.com $>$ ).

8. Serviço virtual de distribuição comercial de música através de assinatura (<http://www.rhapsody. com $>$ ).

9. Disponível em: <http:// www.myspace.com/ music $>$.

10. QUITTNER, John. Free Music for Everybody (Música de graça para todos). Revista Time, edição dupla, p. 100, 6 out. 2008. 
comunicação \& educação • Ano XIV • Número 1 • jan/abr 2009

gravar as músicas - nem oferecê-las para compartilhamento em plataformas como Mule $^{11}$ (programas compartilhadores de arquivos com gerenciadores de download peer-to-peer/ponto-a-ponto) e outras.

Destacamos, ainda, a venda de ringtones (customização de toques de telefone, especialmente para celulares) que já representa importante fonte de receita para gravadoras e produtoras, as quais lucram ao licenciar e oferecer fonogramas nesse formato. Analisando o aspecto simbólico desse tipo de consumo, compreende-se que exibir ringtones personalizados e exclusivos denota que o usuário está em sintonia com os mais recentes lançamentos, atributo extremamente valorizado em diversas tribos atuais.

Na visão do sociólogo polonês Zygmunt Bauman, a promessa de satisfação feita pela sociedade de consumo "só permanece sedutora enquanto [...] o cliente não está plenamente satisfeito" ${ }^{2}$. Essa satisfação total, plena, permanece impossível devido ao ritmo alucinante e incessante com que novos objetos de desejo são oferecidos, tornado obsoletas e descartáveis grande parte das aquisições anteriores.

Voltando à estratégia de lançamento de In Rainbows, observamos que o cronograma estabelecido para a liberação dos diversos formatos da obra parece ter sido criteriosamente elaborado, de modo a atrair o consumidor antenado, sempre ávido por estar entre os primeiros a exibir as novidades do mercado.

Nesse caso, o aparente altruísmo da banda ao lançar primeiramente o álbum para download, a preço estipulado pelo próprio consumidor, pode ser entendido como uma estratégia denominada buzz marketing, na qual o agito propositadamente criado em torno de determinado evento ou produto serve para impulsionar vendas e fortalecer o valor da marca a médio e longo prazo.

Com esse feito, o Radiohead ganhou as manchetes dos principais jornais e revistas especializadas em música em todo o globo. No competitivo mundo da música massiva, ser notícia é vital para continuar no topo. Nessa arena, o pior que pode acontecer é a indiferença do público, condenando o artista ao ostracismo e a um eventual ocaso.

Por outro lado, ao colocar "o dedo na ferida" na polêmica dos preços praticados no mercado fonográfico, o Radiohead intencionalmente posicionase contra a criminalização do download, fomentando a discussão acerca de temas complexos como a pirataria e os direitos autorais nos dias atuais.

\section{CULTURA REMIX, CIBERCULTURA E DIREITOS AUTORAIS}

11. Disponível em: <http:// www.emule.com>.

12. BAUMAN, Zygmunt. Modernidade líquida. Rio de Janeiro: Jorge Zahar, 2001. p. 63.
Como vimos, a disseminação de sites de distribuição e compartilhamento de música na internet desafia a formatação comercial da escuta. Paralelamente, diversos membros da classe artística têm assumido publicamente suas posições acerca de práticas vigentes na cibercultura que, de certa forma, colocam em questão a própria noção de autoria. 
A extrema maleabilidade do som digital favorece um tipo de interatividade até então restrito a especialistas: recorte e colagem de trechos de obras selecionadas são utilizados na confecção de novas versões ou mesmo de novas canções. O problema é que estes remixes nem sempre são autorizados pelo autor da obra original, o que não impede que sejam disseminados em redes de compartilhamento via internet.

Dentre os casos exemplares podemos citar The Grey Album, alvo de processo judicial movido pela gigante EMI, visando impedir sua distribuição, e, simultaneamente, indicado pela crítica especializada como o melhor álbum de hip-hop em 2004.

Lançado pelo Danger Mouse, o polêmico álbum cinza seria resultado do remix de uma das versões a capella (sem instrumentos) do famoso The Black Álbum, do rapper Jay-Z em 2003, aliado a trechos não autorizados extraídos do lendário White Album dos Beatles. Antes do álbum cinza, haviam surgido diversas outras versões, como The Brown Album, de Kev Brown. O Grey Album só ganhou maior notoriedade devido à resposta judicial da EMI, detentora dos direitos da célebre banda de Liverpool.

No Brasil, o compositor e cantor Gilberto Gil estimulou amplo debate sobre a necessidade de se adequar as leis de direitos autorais vigentes aos novos tempos. Durante sua gestão como Ministro da Cultura do governo Lula, o nosso foi um dos primeiros países latino-americanos a aderir às licenças propostas pelo coletivo Creative Commons - CC. Criado pelo advogado e ativista norte-americano Lawrence Lessig, o Creative Commons tornou-se referência na atribuição de licenças alternativas para a regulamentação da distribuição de produtos culturais via internet.

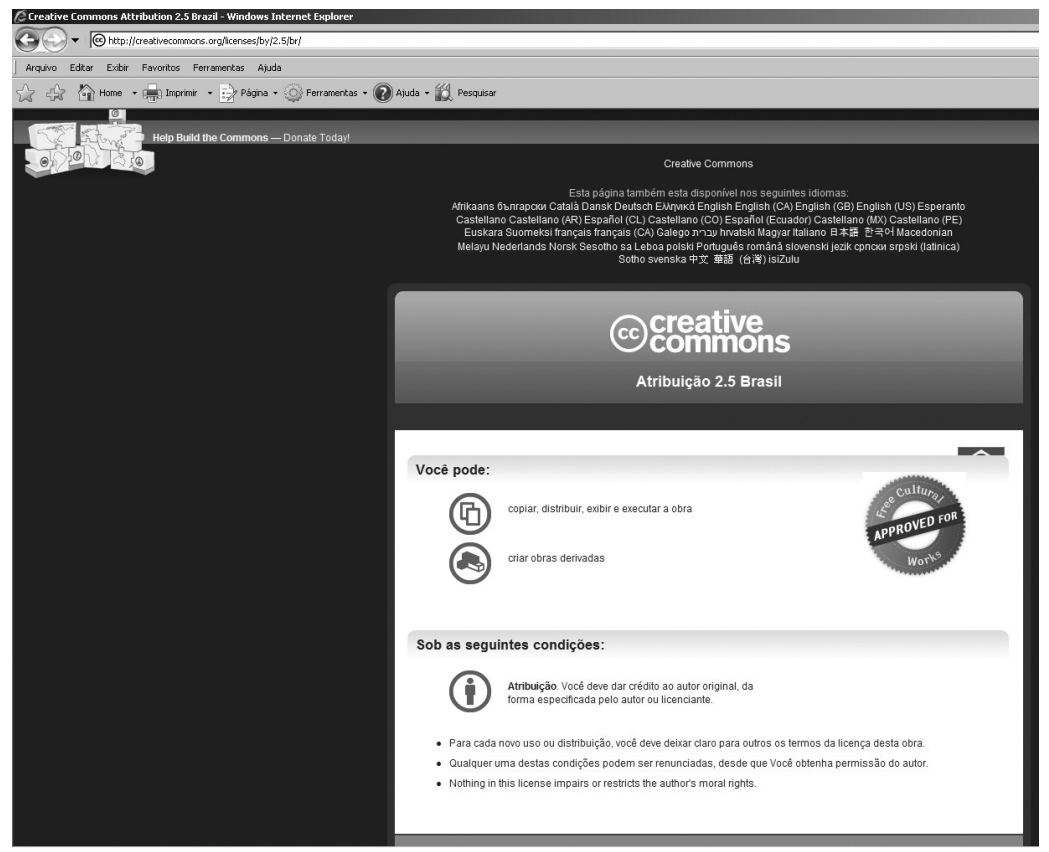

Página brasileira do coletivo Creative Commons - CC.

Disponível em: <http://creativecommons.org/licenses/by/2.5/br/>. 
13. LEMOS, André. Cibercultura: tecnologia e vida social na cultura contemporânea. Porto Alegre: Sulina, 2002.

14. LÉVY, Pierre. Cibercultura. Rio de Janeiro: Ed. 34, 1999.

15. CASTELLS, Manuel. A galáxia da internet: reflexões sobre a internet os negócios e a sociedade. Rio de Janeiro: Jorge Zahar, 2003. comunicação \& educação • Ano XIV • Número 1 • jan/abr 2009

Alegando ser excessiva e ultrapassada a restrição total prevista na legislação vigente de copyrights (onde se lê todos os direitos reservados), Lessig propõe que seja dado ao autor o direito de restringir apenas alguns aspectos de sua obra, selecionando dentre as diversas licenças CC aquela que mais se coadune com suas intenções.

Dentre as licenças propostas pelo coletivo, há a que limita apenas a utilização comercial da obra; outra exige somente que seja citado o nome do autor original em caso de reutilização da obra, dentre outras. Dessa forma fica esclarecido que tipo de uso pode ser feito da versão digital de obras disponíveis na rede mundial de computadores.

Uma das licenças CC foi criada a pedido do próprio Gil, interessado em lançar na rede uma de suas canções para remix. Originalmente oferecida em $\mathrm{CD}$ de mesmo nome, especialmente dirigido ao mercado norueguês, a canção Oslodum ganhou novas versões remixadas por DJs nos quatro cantos do planeta. A prática do remix tornou-se célebre quando DJs da chamada era discoteca, em fins da década de 1970, lançavam suas próprias versões dançantes dos grandes sucessos, adaptadas ao vibrante calor das pistas.

Diversos são os exemplos de sucessos de antigas canções remixadas em novos arranjos ou cujos trechos mais célebres figuram como parte de outras composições. Um exemplo mais recente foi a associação da banda Black Eyed Peas com o pianista e compositor brasileiro Sérgio Mendes, ensejando uma reapropriação do clássico Mas que nada, de Jorge Benjor, em roupagem hiphop. O grande sucesso trouxe a banda e o pianista para uma concorrida apresentação ao vivo nas areias da Praia de Ipanema no réveillon de 2007.

Autores como André Lemos ${ }^{13}$ e Pierre Lévy ${ }^{14}$ identificam o remix no próprio cerne da chamada cibercultura, nascida do ideal da colaboração e do livre compartilhamento de ideias e conteúdo. Sabemos que nos fluxos imateriais do ciberespaço, interesses díspares se intercruzam, nem sempre de modo pacífico. O estudioso espanhol Manuel Castells ${ }^{15}$ percebeu nas tramas da internet um novo modelo de organização das sociedades e dos negócios.

Paralelamente à crescente disponibilização dos acervos das principais gravadoras em sites e plataformas comerciais, milionárias campanhas antipirataria ressaltam o caráter danoso do compartilhamento gratuito para a cadeia produtiva da música. O que certos artistas demonstram é ser possível - e mesmo até desejável - trilhar outros caminhos no conturbado mercado fonográfico atual. É curioso e perturbador observar que a noção de autoria, pedra de toque da noção moderna de propriedade intelectual, figure hoje como calcanhar-de-aquiles da mercadização da produção cultural na cultura do consumo. 


\section{REFERÊNCIAS BIBLIOGRÁFICAS}

BAUMAN, Zygmunt. Modernidade líquida. Rio de Janeiro: Jorge Zahar, 2001.

Vida para o consumo: a transformação das pessoas em mercadoria. Rio de Janeiro: Jorge Zahar, 2008.

CASTELLS, Manuel. A galáxia da internet: reflexões sobre a internet, os negócios e a sociedade. Rio de Janeiro: Jorge Zahar, 2003.

LEMOS, André. Cibercultura: tecnologia e vida social na cultura contemporânea. Porto Alegre: Sulina, 2002.

LÉVY, Pierre. Cibercultura. Rio de Janeiro: Ed. 34, 1999.

QUITTNER, John. Free Music for Everybody (Música livre para todos). Revista Time, edição dupla, 6 out. 2008.

\section{Endereço eletrônico}

$<$ http://www.myspace.com>.

International Federation of the Phonographic Industry (http://www.ifpi.org)

Recording Industry Association of America (http://www.riaa.com)

$<$ http://www.radiohead.com/deadairspace/>

$<$ http://www.itunes.com $>$

$<$ http://www.rhapsody.com>

$<$ http://www.myspace.com/music $>$

$<$ http://www.emule.com $>$ 


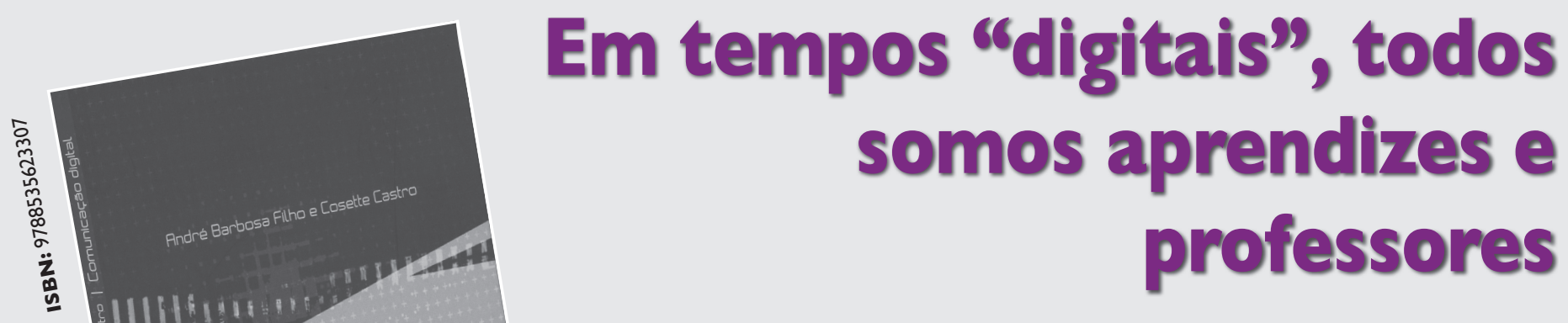

$\mathrm{Na}$ sala de aula, temos, de um lado, estudantes cada vez mais jovens que dominam rapidamente a linguagem das novas tecnologias, e, de outro, professores perplexos, que ainda não sabem como lidar com tais transformações tecnológicas e fluxo de saberes.

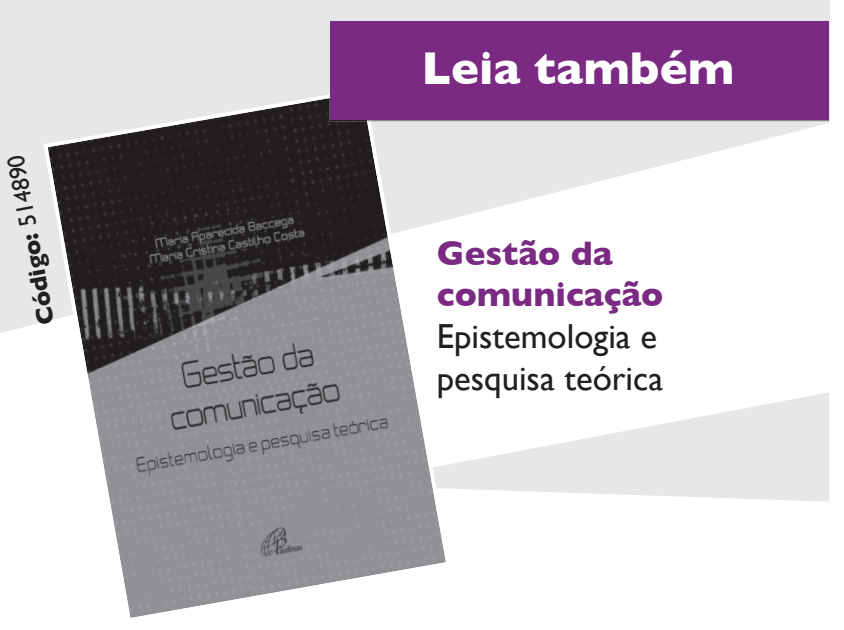

Interessados na democratização do acesso à comunicação como meio para o desenvolvimento pessoal e coletivo, os autores propõem uma reflexão sobre as mídias digitais, desta vez a partir de uma abordagem mais complexa, que une comunicação e educação/aprendizagem. Sob a ótica brasileira e latino-americana, defendem o uso das tecnologias digitais como forma de inclusão social, ou seja, que os cidadãos não apenas tenham acesso às Tecnologias da Informação e da Comunicação, TICs, como possam produzir conteúdos interativos, contar suas histórias, manifestar sua cultura e encontrar novos ofícios e mercados de trabalho.

Segundo os autores, os números de acesso à Internet, horas de uso e participação em comunidades por adolescentes e jovens exigem atenção de pais e educadores. "Cabe à sociedade dar à atual e futura geração a oportunidade de ver esta energia transformada em ações comunicacionais que reproduzam o enorme talento e criatividade de nosso povo para a arte, a informação e a produção de conhecimento", ressalta Cosette. Duas entrevistas com os autores e um glossário encerram a obra, que se destina aos interessados no tema das novas tecnologias e plataformas digitais, da convergência tecnológica e do complexo pensamento do século XXI, que extrapola as fronteiras das ciências, exigindo novos saberes, habilidades e ofícios.

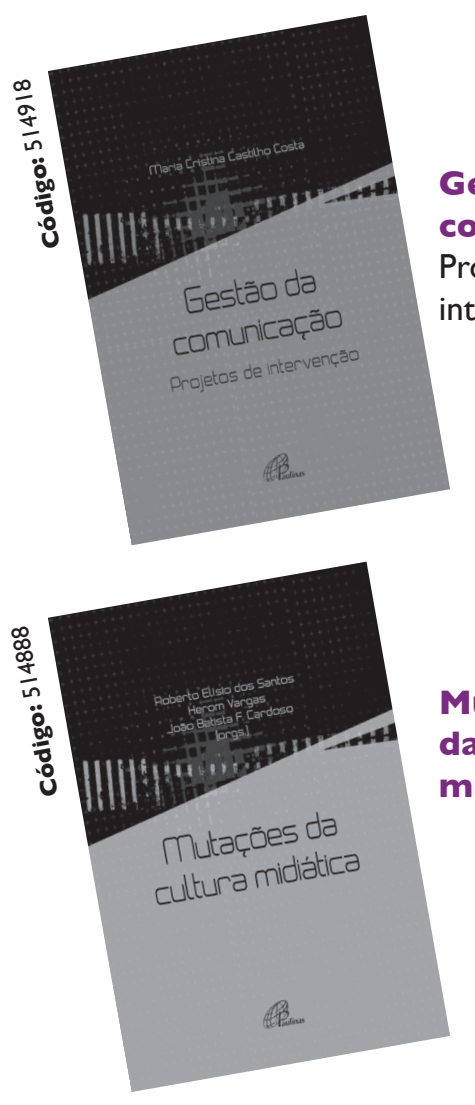

